\title{
Autoren dieses Heftes
}

Thomas Blanke

Ralner Erd

Lothar Frankfurth

Albrecht Funk

Walter Kargl

Siegfred Neufert

Joachim Perels

Helmut Ridder

Christian Riechers

Wolfgang Rosenthal

Richard Schmid

Henning Spangenberg

Ilse Staff

Wolfgang Voegeli

Falco Werkentın

Renate Wiggershaus

Rolf Wiggershaus geb. 1944, Dr. jur., Professor für Arbeitsrecht an der Universität Oldenburg, 29 Oldenburg, Roggemannstr. 19

geb. 1944, Assessor, wissenschaftlicher Mitarbeiter am Institut für Sozialforschung in Frankfurt/M., 6 Frankfurt/M. 90, Metzstr. 6

geb. 1953, stud. jur., I Berlin 36, Lübbener Str. 2

geb. 1948, Dr. rer. pol., wissenschaftlicher Mitarbeiter der Berghof-Stiftung für Konfliktforschung I Berlin 31, Landhausstr. 9

geb. 1945, Rechtsanwalt, 8 München 19, Nibelungenstr. Ia

geb. 1947, erstes juristisches Staatsexamen, Doktorand, 6 Frankfurt I, Schwarzburgstr. 7

geb. 1942, Dr. jur., Akademischer Rat am Seminar für Wissenschaft von der Politik an der TU Hannover, 3 Hannover I, Fliederstr. 4

geb. 1919, Dr. jur., Professor für Offentliches Recht und Wissenschaft von der Politik an der Justus-Liebig-Universität Gießen, 63 Gießen, Hein-Heckroth-Str. S

geb. 1936, Dr. phil., Akademischer Rat am Seminar für Wissenschaft von der Politik an der TU Hannover, 3 Hannover I, Bessemerstr. Is

geb. I951, stud. jur., I Berlin I2, Windscheidstr. 40

geb. I 899, Dr. jur., Oberlandesgerichtspräsident i. R., 7 Stuttgart-Riedenberg, Schafgärten 27

geb. 1944, Rechtsanwalt, I Berlin Is, Meierottostr. I

geb. 1928, Dr. jur., Professor für Offentliches Recht an der Universität Frankfurt/M., 6 Frankfurt/M. 90, Senkkenberganlage $3 \mathrm{I}$

geb. 1946, Assessor, Akademischer Rat an der Fakultät für Rechtswissenschaften der TU Hannover, 3 Hannover I, Kollenrodtstr. I4

geb. 1944, Diplom-Soziologe, wissenschaftlicher Mitarbeiter der Berghof-Stiftung für Konfliktforschung, I Berlin 3 1 , Prinzregentenstr. 2

geb. 1945, Autorin und Ubersetzerin, 6 Frankfurt 50, Amöneburgerstr. 44

geb. 1944, Dr. phil., Autor und Úbersetzer, 6 Frankfurt so, Amöneburgerstr. 44 